\title{
Seleção e caracterização de estirpes de Bacillus thuringiensis eficientes contra a Diatraea saccharalis (Lepidoptera: Crambidae)
}

\author{
Cristina Lima de Macedo(1), Érica Soares Martins( ${ }^{(1)}$, Leonardo Lima Pepino de Macedo(2), \\ Aldaléia Carmo dos Santos ${ }^{(1)}$, Lílian Botelho Praça(1), Luiz Avelar Brandão de Góis( ${ }^{(3)}$ e Rose Gomes Monnerat( ${ }^{(4)}$ \\ (1)Universidade de Brasília, Campus Universitário Darcy Ribeiro, s/no , Asa Norte, CEP 70910-900 Brasília, DF. E-mail: crispepi@yahoo.com.br, \\ esmartins@gmail.com, aldaleia.santos@gmail.com, lilian.praca@embrapa.br (2)Universidade Católica de Brasília, Campus Asa Norte, \\ SGAN 916, Módulo B, CEP 70790-160 Brasília, DF. E-mail: limapepino@yahoo.com.br ${ }^{(3)}$ Triunfo Agro-Industrial Ltda., Boca da Mata, AL. \\ E-mail: avelar.brandao@usinatriunfo.com.br ${ }^{(4)}$ Embrapa Recursos Genéticos e Biotecnologia, Caixa Postal 02372, CEP 70849-970 Brasília, DF. \\ E-mail: rose.monnerat@embrapa.br
}

Resumo - O objetivo deste trabalho foi selecionar e caracterizar estirpes nativas de Bacillus thuringiensis tóxicas a Diatraea saccharalis (Lepidoptera: Crambidae). Cento e seis estirpes pertencentes ao Banco de Bactérias de Invertebrados, da Embrapa Recursos Genéticos e Biotecnologia, foram testadas quanto à toxicidade a $D$. saccharalis, e, as mais tóxicas, caracterizadas por métodos bioquímicos e moleculares. Das 106 estirpes testadas, 16 causaram $100 \%$ de mortalidade em 24 horas. As três estirpes mais tóxicas apresentaram concentração letal média entre 8 e $43 \mathrm{ng} \mathrm{cm}^{-2}$. O perfil proteico das 16 estirpes mostrou a presença de proteínas de 130 e $65 \mathrm{kDa}$, e a caracterização molecular mostrou a presença dos genes tipo cryl e cry2: crylAa, crylAb, crylAc e cry $2 A a$. A concentração letal média de esporos e cristais obtidos a partir de estirpes recombinantes, que expressavam individualmente os genes crylAa, crylAb, crylAc e cry $2 A a$, variou entre 222 e $610 \mathrm{ng} \mathrm{cm}^{-2}$, valores muito superiores aos das estirpes nativas mais tóxicas, que apresentavam possibilidade de expressão simultânea desses genes. Este resultado é indicativo de que há sinergia entre as toxinas. Há interação entre as toxinas de $B$. thuringiensis e seus receptores na broca-do-colmo da cana-de-açúcar.

Termos para indexação: Diatraea saccharalis, controle biológico, ensaio de ligação, proteínas Cry.

\section{Selection and characterization of Bacillus thuringiensis efficient strains against Diatraea saccharalis (Lepidoptera: Crambidae)}

\begin{abstract}
The objective of this work was to select and characterize native strains of Bacillus thuringiensis toxic to Diatraea saccharalis (Lepidoptera: Crambidae). A hundred-and-six strains, belonging to the bank of invertebrate bacteria (Brazil), of Embrapa Genetic Resources and Biotechnology, were tested as to their toxicity to $D$. saccharalis, and the most toxic ones were characterized by biochemical and molecular methods. Out of the 106 tested strains, 16 caused $100 \%$ mortality within 24 hours. The three most toxic strains showed median lethal concentrations between 8 and $43 \mathrm{ng} \mathrm{cm}^{-2}$. The protein profile of the 16 strains showed the presence of 130 and $65 \mathrm{kDa}$ proteins, and the molecular characterization showed the presence of cryland cry 2 type genes: crylAa, crylAb, crylAc, and cry2Aa. The median lethal concentration of spores and crystals obtained from recombinant strains, which individually expressed the genes cry $1 A a, c r y 1 A b, c r y 1 A c$, and $c r y 2 A a$, varied between 222 and $610 \mathrm{ng} \mathrm{cm}^{-2}$, values much higher than the ones of the most toxic native strains, which have the possibility of simultaneously expressing these genes. This result indicates a synergy between the toxins. There are interactions between $B$. thuringiensis toxins and their receptors in the sugarcane borer.
\end{abstract}

Index terms: Diatraea saccharalis, biologic control, binding assays, Cry proteins.

\section{Introdução}

Entre as espécies que atacam a cana, Diatraea saccharalis (Fabr. 1794) (Lepidoptera: Crambidae), conhecida como broca-da-cana, é a que causa mais prejuízos à cultura. Seu hábito alimentar, que se caracteriza pela penetração da lagarta nos colmos da planta, limita seu controle por métodos convencionais (Gitahy et al., 2007). O controle desta praga, no entanto, tem sido realizado com agrotóxicos, apesar dos potenciais riscos desses produtos ao homem e ao ambiente. Assim, agentes de controle biológico são uma alternativa ecológica e economicamente viável (Praça et al., 2004), e o uso de Bacillus thuringiensis é uma 
estratégia promissora no controle de $D$. saccharalis, conforme relatado por Praça et al. (2004) e Gitahy et al.(2007).

Bacillus thuringiensis é uma bactéria do solo, Gram-positiva, aeróbia, da família Bacillaceae, que produz inclusões proteicas cristalinas e esporos. Essas inclusões são compostas por proteínas conhecidas como $\delta$-endotoxinas ou proteínas Cry, muito tóxicas a uma ampla variedade de insetos-praga de importância econômica e também a outros invertebrados (Monnerat \& Bravo, 2000). Várias estirpes de B. thuringiensis, específicas para os insetos das ordens Lepidoptera, Coleoptera e Diptera, têm sido isoladas (Praça et al., 2004).

O mecanismo de ação desta bactéria envolve vários passos, como solubilização do cristal, processamento das toxinas, interações específicas com receptores, união ao receptor e inserção de uma parte da toxina na membrana apical das células intestinais dos insetos. Os receptores responsáveis pela ligação da toxina à membrana tem sido estudados em lepidópteros, para determinar especifidade, toxicidade e mecanismo de ação das toxinas Cry (Bravo et al., 2004). A união aos sítios receptores tem motivado diversos grupos de pesquisa a se dedicarem ao melhor entendimento desse processo (Monnerat \& Bravo, 2000), pois ele é uma etapa determinante da especificidade das toxinas Cry.

A maioria das estirpes de $B$. thuringiensis pode sintetizar mais de um tipo de cristal. Estes podem ser formados por diferentes proteínas Cry, e pode haver casos em que até cinco toxinas são sintetizadas por uma mesma estirpe. A busca por estirpes de B. thuringiensis eficazes contra a broca-da-cana é de grande importância para o manejo desta praga, mas estudos sobre este assunto ainda são limitados.

O objetivo deste trabalho foi selecionar e caracterizar estirpes nativas de Bacillus thuringiensis tóxicas a Diatraea saccharalis (Lepidoptera: Crambidae).

\section{Material e Métodos}

Foram realizadas triagens de 106 estirpes de B. thuringiensis, pertencentes ao Banco de Bactérias de Invertebrados, da Embrapa Recursos Genéticos e Biotecnologia, para selecionar aquelas que possuem potencial para o controle da broca-do-colmo da cana-de-açúcar. Destas, seis eram estirpes recombinantes de $B$. thuringiensis que produzem toxinas individuais Cry1Aa, Cry1Ab, Cry1Ac, Cry1B, Cry1 I e Cry2Aa. As estirpes foram cultivadas em meio de cultura Embrapa, conforme Monnerat et al. (2007), em incubador rotativo, Modelo 3595, a $200 \mathrm{rpm}$ (Labline Instruments, Melrose Park, IL, EUA), a $28^{\circ} \mathrm{C}$ durante 72 horas, até sua completa esporulação.

As culturas bacterianas que causaram mortalidade de $100 \%$ foram diluídas 50 vezes e novamente testadas. As que mantiveram a taxa de mortalidade de lagartas acima de $75 \%$ foram submetidas a novos ensaios, para determinação da concentração letal necessária para matar $50 \%$ da população testada $\left(\mathrm{CL}_{50}\right)$.

Os ensaios foram realizados em copos de plástico de $50 \mathrm{~mL}$, cobertos com tampas de acrílico, que continham $10 \mathrm{~mL}$ de dieta artificial com açúcar $(54 \mathrm{~g})$, farelo de soja (42 g), gérmen de trigo (32 g), ágar (18,8 g), água $(1.000 \mathrm{~mL})$, ácido ascórbico $(2 \mathrm{~g})$, ácido sórbico $(1,2 \mathrm{~g})$, nipagin $(1,8 \mathrm{~g})$ e solução vitamínica (12 g), conforme descrito por King \& Hartley (1985). A dieta foi autoclavada e vertida no fundo dos copos, que foram mantidos sob luz UV por $20 \mathrm{~min}$. A cultura bacteriana $(150 \mu \mathrm{L})$ foi depositada na superfície da dieta. Para cada estirpe, foram feitas três repetições e um controle negativo, livre do patógeno. Após a secagem da cultura bacteriana adicionada à dieta, dez lagartas de segundo instar de $D$. saccharalis foram colocadas em cada copo. O bioensaio foi mantido em sala climatizada a $28 \pm 2^{\circ} \mathrm{C}$, com umidade a $70 \%$ e fotoperíodo de 14 horas de luz e 10 horas de escuro.

A primeira avaliação de mortalidade foi feita 48 horas após o início do ensaio, ocasião em que as lagartas foram transferidas para copos de plástico de $50 \mathrm{~mL}$ com dieta livre do patógeno. No sétimo dia, foi feita a segunda e última avaliação (Praça et al., 2004). Conforme mencionado, as estirpes que mataram 100\% de lagartas foram diluídas 50 vezes e novamente testadas. As que mantiveram a taxa de mortalidade de lagartas acima de $75 \%$ foram utilizadas para a continuação do ensaio. No cálculo da $\mathrm{CL}_{50}$, foram feitas diluições seriadas da cultura bacteriana liofilizada, e o bioensaio foi preparado nas condições anteriormente descritas. Foram testadas dez diluições de cada estirpe. Bacillus thuringiensis subsp. kurstaki HD-1 (Btk) foi utilizado como padrão e controle positivo. Os dados de mortalidade obtidos após sete dias foram analisados mediante análise Probit (Finney, 1971), e a $\mathrm{CL}_{50}$ foi determinada. 
Os perfis proteicos das estirpes tóxicas foram avaliados de acordo com o protocolo de extração de proteínas, descrito por Lecadet et al. (1992), com modificações. As preparações de esporos-cristais foram ressuspendidas em tampão de amostra de proteína, fervidas a $100^{\circ} \mathrm{C}$ por 5 min e analisadas por SDS-PAGE a 10\% (Laemmli, 1970). Foi utilizado o marcador de massa molecular Rainbow, da GE. Para comparação, a estirpe S1450 de B. thuringiensis subsp. kurstaki foi usada como padrão, por se tratar da estirpe referência para lepidópteros.

A extração do DNA total das estirpes selecionadas foi realizada de acordo com a metodologia descrita por Bravo et al. (1998). Foram utilizados oligonucleotídeos para a identificação dos seguintes genes: cryl, cry2, cry 3, cry 4, cry 5, cry 7, cry 8, cry9, cry 10, cry 11, cry 12 , cry 13 , cry 14 , cry 17 , cry 19 , cry 21 , cry 24 , cry 25 , cry 27, cry 29, cry 30, cry 32 , cry 39 , cry 40 , cyt 1 e cyt $2 \mathrm{e}$ específicos na identificação de cryl, cry2, cry4, cry7, cry9 e cryl3 (Ceron et al., 1994, 1995; Bravo et al., 1998; Ibarra et al., 2003). Diferentes oligonucleotídeos foram utilizados nas reações em cadeia das polimerases (PCR). Transferiram-se $5 \mu \mathrm{L}$ do sobrenadante da cultura para um novo tubo de polipropileno de $0,2 \mathrm{~mL}$, que continha $0,5 \mu \mathrm{mol} \mathrm{L} \mathrm{L}^{-1}$ de cada oligonucleotídeo, $0,2 \mu \mathrm{mol} \mathrm{L}{ }^{-1}$ de dNTP mix, tampão de Taq $1 \mathrm{X}$ e $2,5 \mathrm{U}$ de Taq DNA polimerase $(5,0 \mathrm{U})$, o que totalizou $30 \mu \mathrm{L}$ de volume final. As condições de amplificação foram baseadas nas descrições de Ceron et al. (1994, 1995), Bravo et al. (1998) e Ibarra et al. (2003).

Para a análise da reação da PCR, uma alíquota de $25 \mu \mathrm{L}$ de cada produto de PCR foi misturada com $5 \mu \mathrm{L}$ tampão de amostra e aplicada em gel de agarose a 1,5\%. A corrida eletroforética foi realizada em tampão TBE $1 \mathrm{X}$ [Tris-base $\left(0,89 \mathrm{~mol} \mathrm{~L}^{-1}\right)$, ácido bórico $\left(0,88 \mathrm{~mol} \mathrm{~L}^{-1}\right)$, EDTA $0,5 \mathrm{~mol} \mathrm{~L}^{-1}(\mathrm{pH} \mathrm{8,0)].} \mathrm{Após} \mathrm{a} \mathrm{eletroforese,} \mathrm{o} \mathrm{gel}$ foi corado com brometo de etídio, diluído em água, à concentração de $1 \mu \mathrm{g} \mathrm{mL}^{-1}$, por $20 \mathrm{~min}$, e descorado em água destilada por $15 \mathrm{~min}$. O gel foi visualizado em transluminador sob luz UV e fotografado em fotodocumentador Stratagene, Eagle Eye, (PennState Science, University Park, PA, EUA).

As estirpes recombinantes S2211 (Cry1Aa), S2210 (Cry1Ab), S2212 (Cry2Aa) e S2209 (Cry1Ac) foram mantidas a $28^{\circ} \mathrm{C}$ e $200 \mathrm{rpm}$, durante 72 horas, em meio de esporulação ( $8 \mathrm{~g} \mathrm{~L}^{-1}$ de caldo nutriente; $0,25 \mathrm{~g} \mathrm{~L}^{-1}$ de $\mathrm{MgSO}_{4} \cdot 7 \mathrm{H}_{2} \mathrm{O} ; 1 \mathrm{~g} \mathrm{~L}^{-1}$ de $\mathrm{KCl} ; 0,002 \mathrm{~g} \mathrm{~L}^{-1}$ de $\mathrm{MnCl}_{2} .4 \mathrm{H}_{2} \mathrm{O} ; 0,0732 \mathrm{~g} \mathrm{~L} \mathrm{~L}^{-1}$ de $\mathrm{Fe}_{2}\left(\mathrm{SO}_{4}\right) .7 \mathrm{H}_{2} \mathrm{O}$;
0,0056\% de $\mathrm{H}_{2} \mathrm{SO}_{4} ; 0,098 \mathrm{~g} \mathrm{~L}^{-1}$ de $\mathrm{CaCl}_{2}$ ) (Lereclus et al., 1995). Na purificação dos cristais, foi utilizado o protocolo de Thomas \& Ellar (1983). As proteínas foram quantificadas com protein assay (Bio Rad), pelo método de Bradford (Bradford, 1976).

Utilizou-se tripsina, para simulação e observação da ação das enzimas envolvidas no processo de ativação. As proteínas foram incubadas com a enzima durante duas horas a $37^{\circ} \mathrm{C}$, com leve agitação para ativação das toxinas. A concentração da tripsina variou de acordo com a concentração das proteínas, a 10:1 de proteína:enzima. Para inativação da enzima, adicionou-se PMSF a $1 \mathrm{mmol} \mathrm{L}^{-1} \mathrm{e}$, em seguida, foi feita uma centrifugação a $11.180 \mathrm{~g}$ por $10 \mathrm{~min}$, e o sobrenadante foi recuperado. A observação da integridade das proteínas e a determinação de sua massa molecular foi realizada em gel de poliacrilamida, a $12 \%$.

As proteínas ativas Cry1Aa, Cry1Ab, Cry1Ac e Cry2Aa foram biotiniladas com auxílio do kit ECL Protein Biotinylation System (Amersham), de acordo com as recomendações do fabricante. Em seguida, elas foram submetidas à eletroforese em gel desnaturante de poliacrilamida a $12 \%$. Uma vez detectada a atividade tóxica de Cry1Aa, Cry1Ab, Cry1Ac e Cry2Aa, analisaram-se estas proteínas quanto à capacidade de ligação ao intestino médio das lagartas da broca-da-cana. A partir dos intestinos médios de D. saccharalis de quarto instar, foram retiradas as vesículas da "borda em escova" da membrana apical das células do intestino ("brush border mambrane vesicles" - BBMV), com auxilio de pinça. Essas vesículas foram lavadas e conservadas em solução-tampão (manitol 200 mmol L-1, DDT $1 \mathrm{mmol} \mathrm{L}^{-1}$ e HEPES-Tris $1 \mathrm{mmol} \mathrm{L}^{-1}$, $\mathrm{pH} 7,4)$ a $-80^{\circ} \mathrm{C}$ (Wolfesberger et al., 1987).

O ensaio de ligação foi realizado conforme Aranda et al. (1996), para observar a ligação das proteínas testadas às BBMVs extraídas do intestino médio.

\section{Resultados e Discussão}

Dezesseis estirpes nativas, das 106 testadas, causaram $100 \%$ de mortalidade, e quatro das estirpes recombinantes de $B$. thuringiensis, que expressavam individualmente as toxinas Cry1 Aa, Cryl Ab, Cry1Ac e Cry2Aa, também apresentaram toxicidade à $D$. saccharalis. As estirpes tóxicas pertenciam aos sorotipos kurstaki (S1258, S1264, S2193 e S2195), tolworthi (S1303 e S1304), aizawai (S1295), galleriae (S1298) e morrissoni (S1301). Resultados da atividade 
tóxica de estirpes de $B$. thuringiensis, pertencentes aos sorotipos kurstaki e tolworthi, contra D. saccharalis já haviam sido relatados por Gitahy et al. (2007). Dados semelhantes foram obtidos por Rosas-García (2006), com isolado de sorotipo kurstaki, que demonstrou atividade tóxica contra a broca-da-cana no México. No presente trabalho, as estirpes pertencentes a esses sorotipos também foram tóxicas; além disso, foram detectadas estirpes pertencentes aos sorotipos aizawai, galleriae e morrissoni. As subespécies aizawai, kurstaki e galleriae normalmente apresentam as toxinas Cry1 Aa, Cry1Ab, Cry1Ac, Cry2Aa e Cry2Ab, descritas como tóxicas a insetos da ordem Lepidoptera (Monnerat et al., 1999).

As estirpes que causaram mais de $75 \%$ de mortalidade após diluição por 50 vezes foram: S602, S1264 e S1301. Entre elas, a mais tóxica à $D$. saccharalis foi a S602 ( $\mathrm{CL}_{50}$ de 8,96 $\left.\mathrm{ng} \mathrm{cm}^{-2}\right)$, seguida do padrão Btk $\left(12,46 \mathrm{ng} \mathrm{cm}^{-2}\right)$ e da estirpe S1264 $\left(20,43 \mathrm{ng} \mathrm{cm}^{-2}\right)$ com valores de $\mathrm{CL}_{50}$ estatisticamente semelhantes, porém diferentes da estirpe S1301 (43,28 $\left.\mathrm{ng} \mathrm{cm}^{-2}\right)$ (Tabela 1).

Por meio de análise do perfil proteico, foi possível observar que as preparações das estirpes selecionadas eram compostas de dois polipeptídeos principais, de aproximadamente 130 e $65 \mathrm{kDa}$, que correspondem ao perfil do padrão Btk (Figura 1) (Höfte et al., 1988). O perfil de $130 \mathrm{kDa}$ está relacionado ao padrão característico das proteínas Cry, eficientes contra coleópteros e lepidópteros, e o perfil de $65 \mathrm{kDa}$ é característico das proteínas do grupo Cry2, ativa contra lepidópteros e dípteros (Bravo et al., 2004).

$\mathrm{O}$ perfil gênico variou entre as estirpes. Os amplicons produzidos com maior frequência foram os correspondentes aos genes cryl $A b$ e $c r y 2 A b$ (13 estirpes), crylAa e cry $2 A a$ (9 estirpes), crylAd e crylE (6 estirpes) e crylAc (5 estirpes). Três estirpes expressaram amplicons correspondentes aos genes crylF e crylG, enquanto amplicons para os genes

Tabela 1. Concentração letal para 50\% da população testada $\left(\mathrm{CL}_{50}\right)$ das estirpes de Bacillus thuringiensis, no controle de lagartas de segundo instar de Diatraea saccharalis ${ }^{(1)}$.

\begin{tabular}{lc}
\hline Estirpe & $\mathrm{CL}_{50}\left(\mathrm{ng} \mathrm{cm}^{-2}\right)$ \\
\hline S602 & $8,96(5,46-14,61) \mathrm{a}$ \\
S1264 & $20,43(14,53-38,71) \mathrm{ab}$ \\
S1301 & $43,28(19,30-72,73) \mathrm{b}$ \\
S1450(Btk) & $12,46(2,34-20,46) \mathrm{ab}$ \\
\hline
\end{tabular}

${ }^{(1)}$ Médias seguidas por letras iguais não diferem entre si, pela análise Probit, a $5 \%$ de probabilidade. cry $1 B$, cry $1 C$ e $c r y l D$ foram detectados apenas uma vez (Tabela 2). A variabilidade de genes detectados nas estirpes expande o espectro de hospedeiros da bactéria (Agaisse \& Lereclus, 1995). Os outros iniciadores utilizados não produziram fragmentos de tamanho esperado, o que indica que as estirpes não possuem os genes cry3, cry4, cry5, cry 7, cry8, cry9, cry 10 , cry 11 , cry 12, cry 13, cry 14, cry 17, cry 19, cry 21, cry 24, cry 25 , cry 27, cry 29, cry 30, cry 32, cry 39 , cry 40 , cyt 1 e cyt 2.

As estirpes S602 e S1258 apresentaram perfil gênico e proteico semelhantes entre si, ou seja, proteína de $130 \mathrm{kDa}$, correspondente aos genes crylAa, crylAb e cry $1 A c$, e proteína de $65 \mathrm{kDa}$, correspondente aos genes cry $2 A a$ e cry $2 A b$. A estirpe $\mathrm{S} 1264$ apresentou os mesmos genes, exceto o gene cry $2 A b$, mas não apresentou no perfil proteico a proteína de $65 \mathrm{kDa}$ (Figura 1). É possível que esta proteína Cry2Aa

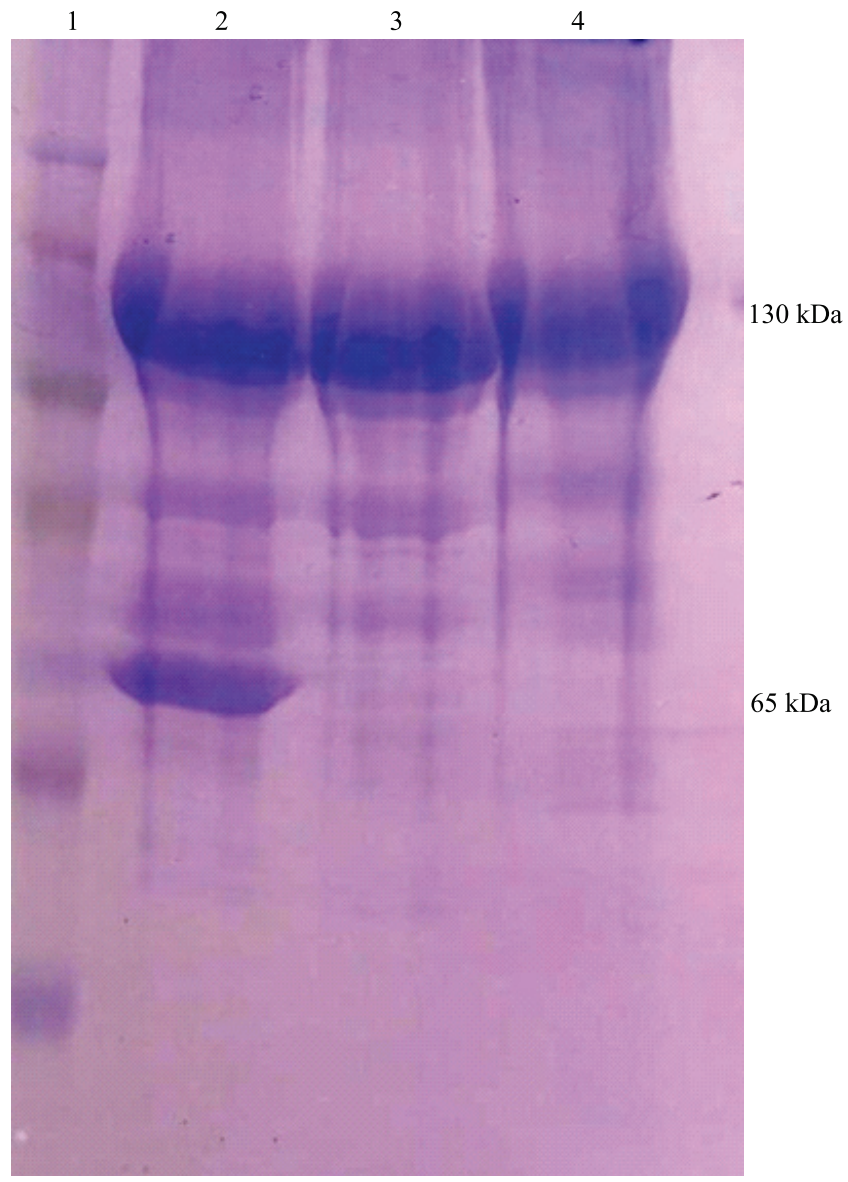

Figura 1. SDS-PAGE (12\%) do complexo esporo-cristal das estirpes de Bacillus thuringiensis S602, S1264 e S1301. 1, marcador de massa molecular Rainbow (GE); 2, S602; 3: S1264 e 4: S1301. 
não seja expressa, ou que seja expressa em baixas quantidades, indetectáveis nas preparações. Todas as outras combinações gênicas foram diferentes entre si.

Com os ensaios realizados com as proteínas Cry individuais, observou-se que a $\mathrm{CL}_{50}$ das proteínas Cry1Aa, Cry1Ab, Cry1Ac, Cry2Aa variou entre $222 \mathrm{e}$ $610 \mathrm{ng} \mathrm{cm}^{-2}$ (Tabela 3). Ainda que as toxinas Cry1 $\mathrm{Ab}$ e Cry2Aa tenham apresentado resultados de $\mathrm{CL}_{50}$ mais baixos (222 e $278 \mathrm{ng} \mathrm{cm}^{-2}$, respectivamente) todas as proteínas apresentaram resultados de toxicidade semelhantes.

As estirpes tóxicas selecionadas no presente trabalho e a estirpe padrão Btk apresentaram $\mathrm{CL}_{50}$ de 8 a $43 \mathrm{ng} \mathrm{cm}^{-2}$ (Tabela 1), bastante inferior e significativamente diferente ao das toxinas puras, o que indica haver sinergia entre as toxinas. Outros autores relataram que a toxicidade das proteínas Cry pode estar relacionada à ação sinergística existente em algumas estirpes, ou seja, que ela é potencializada quando duas ou mais proteínas Cry agem em conjunto. Isso torna necessária a realização e a análise de ensaios com proteínas individuais e em conjunto, para confirmar a toxina responsável pela mortalidade (Praça et al., 2004).

As toxinas utilizadas neste trabalho foram descritas como tóxicas a vários insetos da ordem Lepidoptera: CrylAa para Manduca sexta, Bombyx mori, Heliothis

Tabela 2. Perfis proteicos $(\mathrm{kDa})$ e conteúdo gênico, presentes em estirpes de Bacillus thuringiensis tóxicas a lagartas de segundo estágio de Diatraea saccharalis.

\begin{tabular}{|c|c|c|}
\hline Estirpe & Conteúdo gênico & $\begin{array}{c}\text { Perfil } \\
\text { proteico }\end{array}$ \\
\hline S602 & cry $1 A a$, cry $1 A b$, cry $1 A c$, cry $2 A a$, cry $2 A b$ & $130-65$ \\
\hline S1258 & $\operatorname{cry} 1 A a$, cry $1 A b$, cry $1 A c$, cry $2 A a$, cry $2 A b$ & $130-65$ \\
\hline S1264 & $\operatorname{cry} 1 A a, \operatorname{cry} 1 A b, \operatorname{cry} 1 A c, \operatorname{cry} 2 A a$ & 130 \\
\hline S1287 & $\operatorname{cry} 1 A b, \operatorname{cry} 1 A d, \operatorname{cry} l F, \operatorname{cry} 1 G$ & 130 \\
\hline S1289 & cry $1 A b$, cry $1 A d$, cry $2 A b$ & $130-65$ \\
\hline S1295 & $\operatorname{cry} 1 A a, \operatorname{cry} 1 A b, \operatorname{cry} 1 A d, \operatorname{cry} 1 C, \operatorname{cry} 1 E, \operatorname{cry} 2 A b$ & 65 \\
\hline S1298 & $\operatorname{cry} 1 F, \operatorname{cry} 1 G, \operatorname{cry} 2 A b$ & $130-65$ \\
\hline S1301 & $\operatorname{cry} 1 A b, \operatorname{cry} 1 F, \operatorname{cry} 1 A c, \operatorname{cry} 1 D, \operatorname{cry} 1 G, \operatorname{cry} 2 A a$, cry $2 A b$ & 130 \\
\hline S1303 & $\operatorname{cry} 1 A b, \operatorname{cry} 1 E, \operatorname{cry} 2 A a$ & $130-65$ \\
\hline S1304 & $\operatorname{cry} 1 A b, \operatorname{cry} 1 E, \operatorname{cry} 2 A a, \operatorname{cry} 2 A b$ & $130-65$ \\
\hline S1307 & $\operatorname{cry} 1 A a, \operatorname{cry} 1 A b, \operatorname{cry} 1 B, \operatorname{cry} 1 E, \operatorname{cry} 2 A a, \operatorname{cry} 2 A b$ & $130-65$ \\
\hline S1664 & cry $1 A a$, cry $2 A b$ & 130 \\
\hline S1979 & cry $1 A a$, cry $1 A b$, cry $1 A c$, cry $1 A d$, cry $2 A a$, cry $2 A b$ & $130-65$ \\
\hline S2021 & cry $1 A a$, cry $1 A d$, cry $2 A b$ & 130 \\
\hline S2193 & cry $1 A a$, cry $1 A b$, cry $1 E$, cry $1 F$, cry $2 A b$ & 130 \\
\hline S2195 & cry $1 A b$, cry $1 A d$, cry $1 E$, cry $2 A a$, cry $2 A b$ & $130-65$ \\
\hline $\mathrm{S} 1450^{(1)}$ & $\operatorname{cry} 1 A a, \operatorname{cry} 1 A b, \operatorname{cry} 1 A c$, cry $2 A a, \operatorname{cry} 1 B$ & $130-65$ \\
\hline
\end{tabular}

${ }^{(1)}$ Estirpe padrão btk. virescens, Spodoptera exigua, Ostrinia nubilalis e Thaumetopoea pityocampa (Van Frankenhuyzen, 2009); Cry1Ab para T. pityocampa, Earias insulana e Chilo suppressalis (Sharma et al., 2011); Cry1Ac para Tecia solanivora, Lymantria dispar e B. mori, (Pigott \& Ellar, 2007); e Cry2Aa para Plutella xylostella e H. virescens (Monnerat et al., 1999).

As BBMV de D. saccharalis apresentaram ligações, quando submetidas à marcação das proteínas biotiniladas Cry1Aa, Cry1Ab, Cry1Ac e Cry2Aa (Figura 2). A presença do sinal significa que ocorreu a ligação entre as proteínas Cry e os receptores presentes à superfície do intestino médio das lagartas da $D$. saccharalis. Todas as proteínas solúveis ligaramse aos possíveis receptores presentes no intestino médio das lagartas. Este tipo de interação depende da conformação em que as duas estruturas se encontram. Segundo López-Pazos et al. (2010) as toxinas Cry1 e Cry2 se ligam a receptores específicos nas microvilosidades de células epiteliais do inseto-alvo.

Nas ligações obtidas com as proteínas e os receptores intestinais, ficaram evidentes as variações da intensidade de marcação. Diferentes toxinas Cry podem compartilhar o mesmo receptor ou podem ligar-se a diferentes receptores presentes na membrana intestinal do inseto. Aminopeptidases e caderinas foram relatadas como possíveis receptores das toxinas Cry em lepidópteros (Hernández et al., 2004).

A variação da suscetibilidade às toxinas de $\mathrm{Bt}$ foi descrita em populações de Plutella xylostella (González-Cabrera et al., 2003). Além disso, proteínas entre 65 e 71 kD, como Cry2Aa e Cry2Ac, apresentam toxicidade a lepidópteros e dípteros, enquanto $\mathrm{Cry} 2 \mathrm{Ab}$ tem atividade somente contra lepidópteros (Bravo et al., 2004). As proteínas Cry2Aa não possuem os mesmos receptores das proteínas Cry1Aa para alguns lepidópteros (Karim \& Dean, 2000).

Tabela 3. Concentração letal das toxinas Cry de Bacillus thuringiensis necessária para matar $50 \%$ da população testada $\left(\mathrm{CL}_{50}\right)$, avaliadas individualmente, contra lagartas de segundo instar de Diatraea saccharalis ${ }^{(1)}$.

\begin{tabular}{lc}
\hline Toxina pura & $\mathrm{CL}_{50}\left(\mathrm{ng} \mathrm{cm}^{-2}\right)$ \\
\hline Cry1Aa (S2211) & $610,75(364,76-1.037,10) \mathrm{a}$ \\
Cry1Ab (S2010) & $222,5(50,58-681,10) \mathrm{a}$ \\
Cry1Ac (S2009) & $327,56(186,90-615,83) \mathrm{a}$ \\
Cry2Aa (S2212) & $278,28(136,32-533,25) \mathrm{a}$ \\
\hline
\end{tabular}

${ }^{(1)}$ Médias seguidas por letras iguais não diferem entre si, pela análise Probit.

Pesq. agropec. bras., Brasília, v.47, n.12, p.1759-1765, dez. 2012 

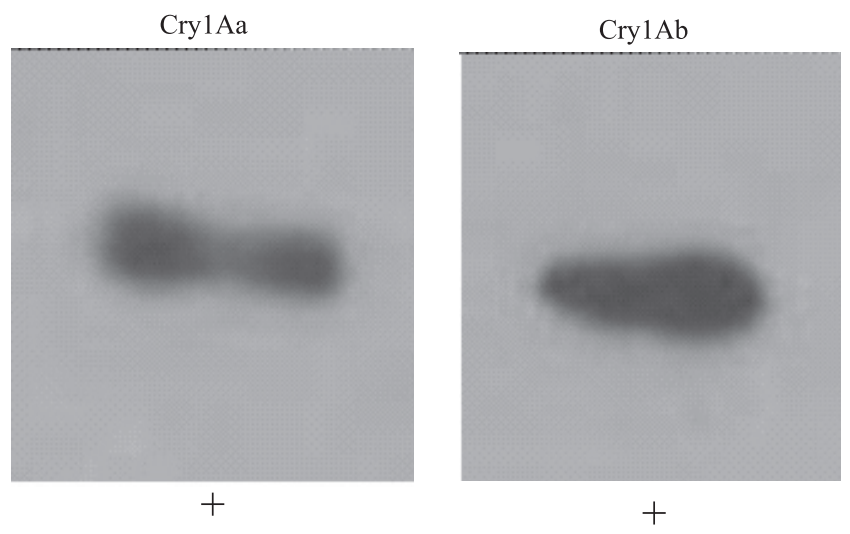

Cry1Ac
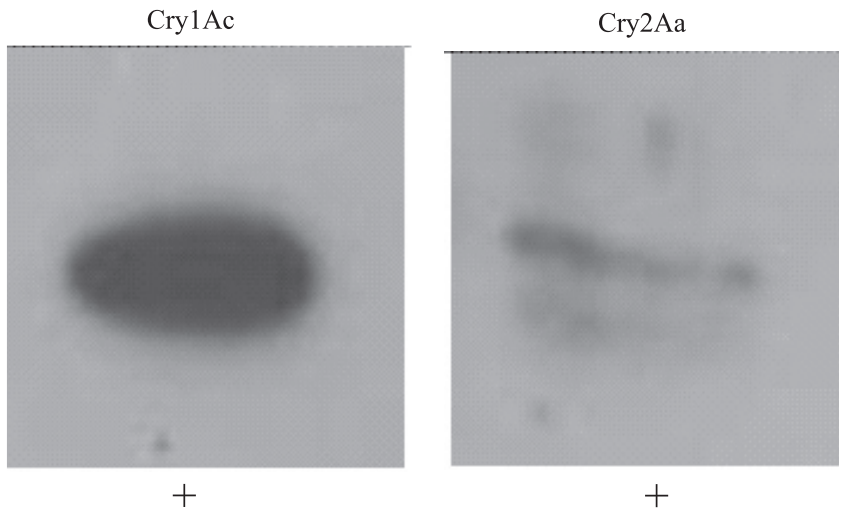

Figura 2. Proteínas ativadas e biotiniladas Cry1Aa, Cry1Ab, Cry1Ac e Cry2Aa, ligadas aos receptores intestinais de Diatraea saccharalis. Os sinais positivos $(+)$ indicam a ligação das proteínas aos receptores.

\section{Conclusões}

1. Há interação entre as toxinas de B. thuringiensis e seus receptores na broca-do-colmo da cana-de-açúcar.

2. As estirpes de Bacillus thuringiensis S602, S1264 e S1301 são eficientes contra lagartas de Diatraea saccharalis.

3. As proteínas testadas Cry1Aa, Cry1Ab, Cry1Ac e Cry2Aa se ligam aos receptores de membrana do intestino médio das lagartas de D. saccharalis, o que mostra a ação tóxica destas proteínas contra este inseto.

\section{Agradecimentos}

À Coordenação de Aperfeiçoamento de Pessoal de Nível Superior (Capes) e à Empresa Brasileira de Pesquisa Agropecuária, pelo apoio financeiro.

\section{Referências}

AGAISSE, H.; LERECLUS, D. How does Bacillus thuringiensis produce so much insecticidal crystal protein? Journal of Bacteriology, v.177, p.6027-6032, 1995.

ARANDA, E.; SANCHEZ, J.; PERFEROEN, M.; GÜERECA, L.; BRAVO, A. Interactions of Bacillus thuringiensis crystal proteins with the midgut ephitelial cells of Spodoptera frugiperda (Lepidoptera: Noctuidae). Journal of Invertebrate Pathology, v.68, p.203-212, 1996.

BRADFORD, M.M. A rapid and sensitive method for the quantitation of microgram quantities protein utilizing the principle of protein dye biding. Analytical Biochemistry, v.72, p.248-254, 1976.

BRAVO, A.; GÓMEZ, I.; CONDE, J.; MUÑOZ-GARAY, C.; SÁNCHEZ, J.; MIRANDA, R.; ZHUANG, M.; GILL, S.S.; SOBERÓN, M. Oligomerization triggers binding of a Bacillus thuringiensis Cryl Ab pore-forming toxin to aminopeptidase $\mathrm{N}$ receptor leading to insertion into membrane microdomains. Biochimica et Biophysica Acta/Biomembranes, v.1667, p.38-46, 2004.

BRAVO, A.; SARABIA, S.; LOPEZ, L.; ONTIVEROS, H.; ABARCA, C.; ORTIZ,M.; LINA, L.; VILLA-LOBOS, F.J.; NUÑEZ-VALDEZ, M.E.; SOBERÓN, M.; QUINTERO, R. Characterization of cry genes in Mexican Bacillus thuringiensis strain collection. Apllied and Enviromental Microbiology, v.64, p.4965-4972, 1998.

CERON, J.; COVARRUBIAS, L.; QUINTERO, R.; ORTIZ, A.; ORTIZ, M.; ARANDA, E.; LINA, L.; BRAVO, A. PCR analysis of the cryI insecticidal crystal family genes from Bacillus thuringiensis. Applied and Environmental Microbiology, v.60, p.353-356, 1994.

CERON, J.; ORTIZ, A.; QUINTERO, R.; GUERECA, L.; BRAVO, A. Specific PCR primers directed to identify cryI and cryIII genes within a Bacillus thuringiensis strain collection. Applied and Environmental Microbiology, v.61, p.3826-3831, 1995.

FINNEY, D.J. Probit analysis. Cambridge: Cambridge University, 1971. 333p.

GITAHY, P. de M.; SOUZA, M.T. de; MONNERAT, R.G.; ARRIGONI, E.B.; BALDANI, J.I. A Brazilian Bacillus thuringiensis strain highly active to sugarcane borer Diatraea saccharalis (Lepidoptera: Crambidae). Brazilian Journal of Microbiology, v.38, p.531-537, 2007.

GONZÁLEZ-CABRERA, J.; ESCRICHE, B.; TABASHNIK, B.E.; FERRÉ J. Binding of Bacillus thuringiensis toxins in resistant and susceptible strains of pink bollworm (Pectinophora gossypiella). Insect Biochemistry and Molecular Biology, v.33, p.929-935, 2003.

HERNÁNDEZ, C.S.; RODRIGO, A.; FERRÉ, J. Lyophilization of lepidopteran midguts: a preserving method for Bacillus thuringiens toxin binding studies. Journal of Invertebrate Pathology, v.85, p.182-187, 2004.

HÖFTE, H.; RIE, J. van; JANSENS, S.; HOUTVEN, A. van; VANDERBRUGGEN, H.; VAECK, M. Monoclonal 
antibody analysis and insecticidal spectrum of three types of lepidopteran-specific insecticidal crystal proteins of Bacillus thuringiensis. Applied and Environmental Microbiology, v.54, p.2010-2017, 1988.

IBARRA, J.E.; RINCÓN, M.C. del; ORDÚZ, S.; NORIEGA, D.; BENNINTENE, G.; MONNERAT, R.; REGIS, L.; OLIVEIRA, C.M.F. de; LANZ, H.; RODRIGUEZ, M.H.; SÁNCHEZ, S.; PEÑA, G.; BRAVO, A. Diversity of Bacillus thuringiensis strains from Latin America with insecticidal activity against different mosquito species. Applied and Environmental Microbiology, v.69, p.5269-5274, 2003.

KARIM, S.; DEAN, D.H. Toxicity and receptor binding properties of Bacillus thuringiensis delta-endotoxins to the midgut brush border membrane vesicles of the rice leaf folders, Cnaphalocrocis medinalis and Marasmia patnalis. Current Microbiology, v.41, p.276-283, 2000.

KING , E.G.; HARTLEY, G.G. Diatraea saccharalis. In: SINGH, P.; MOORE, R.F. (Ed.). Handbook of insect rearing. Amsterdam: Elsevier, 1985. p.265-270.

LAEMMLI, U.K. Cleavage of structural proteins during the assembly of the head of bacteriophage T4. Nature, v.227, p.680-685, 1970.

LECADET, M.M.; CHAUFAUX, J.; RIBIER, J.E.; LERECLUS, D. Construction of novel Bacillus thuringiensis strains with different insecticidal activities by transduction and transformation. Applied and Environmental Microbiology, v.58, p.840-849, 1992.

LERECLUS, D.; AGAISSE, H.; GOMINET, M.; CHAUFAUX, J. Overproduction of encapsulated insecticidal crystal proteins in a Bacillus thuringiensis spoOA mutant. Nature Biotechnology, v.13, p.67-71, 1995.

LÓPEZ-PAZOS, S.A.; ARIAS, A.C.R.; OSPINA, S.A.; CERÓN, J. Activity of Bacillus thuringiensis hybrid protein against a lepidopteran and a coleopteran pest. FEMS Microbiology Letters, v.302, p.93-98, 2010.

MONNERAT, R.G.; BATISTA, A.C.; MEDEIROS, P.T. de; MARTINS, É.S.; MELATTI, V.M.; PRAÇA, L.B.; DUMAS, V.F.; MORINAGA, C.; DEMO, C.; GOMES, A.C.M.; FALCÃO, R.; SIQUEIRA, C.B.; SILVA-WERNECK, S.; BERRY, C. Screening of Brazilian Bacillus thuringiensis isolates active against Spodoptera frugiperda, Plutella xylostella and Anticarsia gemmatalis. Biological Control, v.41, p.291-295, 2007.

MONNERAT, R.G.; BRAVO, A. Proteínas bioinseticidas produzidas pela bactéria Bacillus thuringiensis: modo de ação e resistência. In: MELO, I.S. de; AZEVEDO, J.L. de (Ed.). Controle biológico. Jaguariúna: Embrapa Meio Ambiente, 2000. v.3, p.163-200.

MONNERAT, R.; MASSON, L.; BROUSSEAU, R.; PUSZTAI-CAREY, M.; BORDAT, D.; FRUTOS, R. Differential activity and activation of Bacillus thuringiensis insecticidal proteins in diamondback moth, Plutella xylostella. Current Microbiology, v.39, p.159-162, 1999.

PIGOTT, C.R.; ELLAR, D.J. Role of receptors in Bacillus thuringiensis crystal toxin activity. Microbiology and Molecular Biology Reviews, v.71, p.255-281, 2007.

PRAÇA, L.B.; BATISTA, A.C.; MARTINS, É.S.; SIQUEIRA, C.B.; DIAS, D.G. de S.; GOMES, A.C.M.M.; FALCÃO, R.; MONNERAT, R.G. Estirpes de Bacillus thuringiensis efetivas contra insetos das ordens Lepidoptera, Coleoptera e Diptera. Pesquisa Agropecuária Brasileira, v.39, p.11-16, 2004.

ROSAS-GARCÍA, N.M. Laboratory and field tests of spray-dried and granular formulations of a Bacillus thuringiensis strain with insecticidal activity against the sugarcane borer. Pest Management Science, v.62, p.855-861, 2006.

SHARMA, P.; NAIN, V.; LAKHANPAUL, S.; KUMAR, P.A. Binding of Bacillus thuringiensis Cry1A toxins with brush border membrane vesicles of maize stem borer (Chilo partellus Swinhoe). Journal of Invertebrate Pathology, v.106, p.333-335, 2011.

THOMAS, W.E.; ELLAR, D.J. Mechanism of action of Bacillus thuringiensis var. israelensis insecticidal delta-endotoxin. FEBS Letters, v.154, p.362-368, 1983.

VAN FRANKENHUYZEN, K. Insecticidal activity of Bacillus thuringiensis crystal proteins. Journal of Invertebrate Pathology, v.101, p.1-16, 2009.

WOLFERSBERGER, M.G.; LUETHY, P.; MAURER, P.; PARENTI, P.; SACCHI, V.F.; GIORDANA, B.; HANOZET, G.M. Preparation and partial characterization of amino-acid transporting brush border membrane vesicles from the larval midgut of the cabbage butterfly (Pieris brassicae). Comparative Biochemistry and Physiology, v.86, p.301-308, 1987.

$\overline{\text { Recebido em } 24 \text { de abril de } 2012 \text { e aprovado em } 5 \text { de novembro de } 2012}$ 